\title{
EI Desarrollo de Viviendas de Interés Social y la Recuperación de Plusvalías en el Centro de Guayaquil: ¿Restricción u Oportunidad?
}

\author{
The Development of Social Housing and Value Capture in the Centre of \\ Guayaquil: Restriction or Opportunity?
}

Alina Alexandra Delgado Bohorquez ${ }^{1}$

Recibido: 08 de julio de 2016

Aceptado: 03 de diciembre de 2016

\section{Resumen}

La recuperación de los centros urbanos es una tarea a la que se han abocado los gobiernos de países de América Latina desde hace algunos años y que sigue a la tendencia implantada desde Europa y Estados Unidos. Los mayores costos del desarrollo periurbano y el elevado deterioro de los sectores centrales de las ciudades con la consecuente subutilización de recursos de infraestructura ha despertado un renovado interés por potencializar el desarrollo de estas áreas. En el corazón urbano de la ciudad de Guayaquil se encuentran importantes ejes viales como las calles Quito y Machala. Existen, sin embargo, a lo largo de estas vías solares vacíos, edificaciones obsoletas o en desuso, destinos comerciales no compatibles con la dinámica urbana, ausencia de áreas verdes e inseguridad. El objetivo del presente artículo fue analizar estrategias e instrumentos de gestión territorial que pudieran ser aplicables para la recuperación de plusvalías y el financiamiento de proyectos de vivienda social en el centro de Guayaquil. Se planteó la hipótesis de que a través de la utilización de estos instrumentos se podrían atraer inversiones al centro, y al mismo tiempo asegurar la inclusión de vivienda social, mejorar la calidad de los espacios públicos y contribuir a recuperar la memoria histórica del centro. La metodología utilizada surge de conceptualizaciones, estudio de casos y análisis de aplicabilidad de instrumentos de gestión para la renovación urbana del centro. Se concluye con una reflexión acerca de cómo las visiones diversas de la ciudad (la de las elites y de los grupos de menores ingresos) pueden y deben ser integradas, por medio de la aplicación de instrumentos de recuperación de plusvalías enmarcados dentro de la discusión del derecho a la vivienda, la ciudad y a la función social de la propiedad.

Palabras clave: centros urbanos, gestión del suelo, Guayaquil, recuperación de plusvalías, regeneración, vivienda social.

\begin{abstract}
The revitalization of the urban centers is an endeavor towards which governments of Latin American have been devoted since some years, following the trend transferred from Europe and United States. The higher costs of city periphery developments and the high level of deterioration of city centers with the resulting sub-use of infrastructural resources have originated a renovated interest into promoting these areas development. At the heart of the urban center of Guayaquil are located main and strategic roads, such as Quito and Machala avenues and Panama Street. Along these arteries, there are empty plots, unused and decayed buildings, commercial non compatibles uses with the urban dynamic, lack of green areas and insecurity in the sector. The objective of this article is to analyze strategies and instruments of territorial management that may be applicable for the recovery of capital gains and financing of social housing projects in Guayaquil center. The hypothesis is that through the use of instrument of territorial management it is possible to attract investments meanwhile assuring the inclusion
\end{abstract}

${ }^{1}$ Facultad de Arquitectura e Ingeniería Civil, Universidad de Especialidades Espíritu Santo. Contacto: adelgadobo@uees.edu.ec 
of social housing; thus, diversifying and improving the quality of public spaces, and helping to restore the historical memory of the city center. The methodology applies the study of conceptualizations, study of cases and the analysis of the applicability of these instruments for the urban renovation of the city center. It concludes with a reflection on how the different views of the city, (the elite and lower income groups) can and should be integrated through the application of instruments of value capture framed within the discussion of the right to housing, the city and the social function of the property.

Keywords: Guayaquil, land management, regeneration, social housing, urban centers, value capture. 


\section{Introducción}

La regeneración y recuperación de los centros urbanos es una tarea a la que se orientaron muchos países de América Latina, siguiendo la tendencia implantada desde Europa y Estados Unidos (Rojas, 2004), asemejándose a casos como Rotterdam en Europa (McCarthy, 1998, p. 339), Boston (en los últimos años) en Estados Unidos y Vancouver en Canadá (Marshall, 2011), en la necesidad de rehabilitar el espacio urbano de estas ciudades por medio de la atracción de capitales, recuperación de la identidad cultural y social e inclusión de la vivienda como uno de los mecanismos para lograr una diversidad de usos y vitalizar la utilización del espacio público.

Entre los problemas urbanos compartidos por los países de América Latina se destaca el deterioro y la subutilización de los espacios centrales de sus ciudades, áreas dotadas de infraestructura, pero con gran cantidad de edificaciones en estado de abandono y decadencia, junto con terrenos vacíos. Los programas de regeneración de estos centros incluyen casos como el proyecto Puerto Madero, en Argentina; la recuperación del centro histórico de Quito en Ecuador; el programa de repoblamiento del centro de Santiago de Chile (Rojas, 2004); la recuperación del centro histórico de la ciudad de Panamá (Espino, 2007); y la propuesta del Malecón 2000 en Guayaquil, también en Ecuador (Delgado, 2013).

Las propuestas recientes (2014-2015) destinadas a revalorizar el centro de la ciudad de Guayaquil por medio de proyectos a implementarse a partir del 2024, con ocasión de celebrarse el Bicentenario de la ciudad y que consisten en la regeneración de los ejes viales Machala y Quito, permiten reevaluar la discusión en torno a la renovación de los centros urbanos y analizar diferentes mecanismos de gestión que, junto con la rehabilitación urbana, la valorización económica y la recuperación de plusvalías de los espacios urbanos centrales y edificaciones, permitan la implementación de proyectos de vivienda de interés social como una forma de dar diversidad al espacio urbano y asegurar, a su vez, las inversiones realizadas (Espino, 2007).

Según datos del Instituto Nacional de Estadísticas y Censos del Ecuador, Censo Nacional de Población - (INEC, 2011), Guayaquil es la ciudad más poblada del Ecuador, con 2.654.264 habitantes y siguiendo una tendencia de crecimiento urbano similar a otras ciudades latinoamericanas, fue expandiéndose desde 1950 desde el centro hacia la periferia, como consecuencia de los movimientos migratorios provenientes del campo y otras ciudades de país. En la actualidad, al año 2016, aun cuando la ciudad no mantiene los niveles de crecimiento de años anteriores (debido al incremento de la migración internacional, bajas tasas de nacimientos y disminución de la migración campo-ciudad) continúa extendiéndose y fragmentándose en la periferia a un ritmo de 336 hectáreas por año (Sánchez, 2014) y con una extensión del área urbana de 34.449 
hectáreas (Delgado, 2013). Al mismo tiempo, el centro de la ciudad perdió su carácter simbólico e importancia económica, generándose un proceso de deterioro en algunas de sus avenidas y calles, como en Quito y Machala, ejes viales que cruzan la ciudad de sur a norte y viceversa.

Adicionalmente, la constatación en los últimos tiempos de los costos del crecimiento periférico ha despertado un renovado interés por proponer proyectos urbanos y programas para la recuperación del centro. Según datos del Departamento de Avalúos y Registros del Municipio de Guayaquil, el crecimiento de la ciudad representa 280 millones de dólares al año que se destinan a atender con servicios las áreas de expansión consolidadas y un crecimiento del área urbana de aproximadamente 150 hectáreas (Núñez, 2011). Al mismo tiempo, se presenta una subutilización de recursos de infraestructura en el centro de la ciudad, al existir solares vacíos y edificios subutilizados, como en el caso de las avenidas Quito y Machala, donde existe un porcentaje de desocupación de solares del $4 \%$ respecto del área total de $270.000 \mathrm{~m}^{2}$, correspondiente a 75 cuadras y 68 edificios subutilizados (Villao, 2015).

Para el presente artículo, la investigación se inició desde conceptualizaciones en torno a la función social de la propiedad, el derecho a la ciudad, la recuperación de plusvalías, y la regeneración urbana junto con la gentrificación como fenómeno que se quiere evitar. A partir de una breve descripción del desarrollo histórico de la ciudad se incluyen dos proyectos: el primero, referente a uno de los mayores proyectos a nivel urbano realizados en Guayaquil, respecto de la renovación del área del malecón del río Guayas, "Malecón 2000"; y un proyecto presentado por la Facultad de Arquitectura e Ingeniería de la Universidad de Especialidades Espíritu Santo al Municipio, como parte de una serie de proyectos que el gobierno local implementaría con proyección al año 2024, con ocasión de su Bicentenario. Seguidamente, se realizó un análisis de los instrumentos de gestión urbana que podrían ser aplicables al contexto del centro, considerando la multiplicidad de visiones de la ciudad diversa, y con esto las dificultades, posibilidades y oportunidades de estos instrumentos para asegurar la inclusión de vivienda social, al mismo tiempo que la recuperación de plusvalías e inversiones de los procesos de renovación y rehabilitación urbana.

\section{Conceptualizaciones}

Actualmente, en las ciudades se discuten los alcances de los instrumentos de gestión y financiamiento urbano para lograr el desarrollo económico en un marco de mayor equidad social e integración urbana, lo que le agrega complejidad al debate que existe actualmente respecto de la planificación y gestión urbana en el contexto ecuatoriano de la implementación de una ley de suelos como propuesta del gobierno central (MIDUVI, 2014), así como también 
de la socialización de esta con los diferentes sectores de la sociedad y niveles de gobierno. Esto nos lleva a pensar en nuevos paradigmas para el desarrollo urbano y la forma en que la normativa los aborda respecto de la función social de la propiedad, el derecho a la ciudad y la recuperación de plusvalías. Se busca, a su vez, una revitalización de los centros urbanos que, como en el caso de Guayaquil, han ido perdiendo su carácter central y protagónico, propiciando el deterioro, la subutilización de espacios y la pérdida de inversión de capitales a lo largo de avenidas principales del centro de la urbe.

\section{La regeneración o recuperación de áreas centrales}

Cuando en este estudio se habla de recuperación de áreas centrales se hace referencia a la serie de acciones que el gobierno pueda emprender para lograr la rehabilitación y el mejoramiento económico, social y físico de una zona central urbana ya existente, en contraposición al desarrollo de nuevos asentamientos o infraestructura en la periferia. En este estudio el término recuperación se utiliza enfatizando los procesos económicos y sociales de este tipo de intervención (Rojas, 2004). Las tendencias de urbanización en América Latina en la última década han marcado un cambio de patrón de crecimiento y un regreso a lo que Carrión denomina "la ciudad construida", o "la ciudad existente" (Carrión, 2007, p. 19), significando con esto un regreso al centro de las ciudades y un cambio de dirección al proceso de expansión urbano. Sin embargo, estos procesos han degenerado al mismo tiempo en el deterioro y decadencia de los centros históricos, al haber perdido su carácter simbólico y generar una obsolescencia económica, funcional y física (Inzulza-Contardo, 2016). A medida que la ciudad se extiende, algunas áreas que antes pertenecieron a la periferia se hacen atractivas para la localización de centros comerciales y equipamientos con lo cual se genera un modelo de ciudad policéntrica (Fuentes y Sierralta, 2004). Este tipo de crecimiento representa el abandono de las áreas centrales tradicionales que se vacían de las clases sociales altas y medias que buscan los terrenos mejor valorados de las urbanizaciones en la periferia, además del desplazamiento de actividades económicas dinámicas generadoras de empleos y servicios, las que son reemplazadas por actividades productivas 0 de servicios de menor productividad o informales, así como también por familias de menores ingresos que subarriendan espacios de manera informal, generando tugurios y hacinamientos (Etienne, 1975), cuya conformación está relacionada con los procesos urbanos, económicos y sociales que se viven en ellas (Candia, 2007).

En las áreas centrales en proceso de deterioro es común encontrar pequeñas empresas de producción artesanal, solares o inmuebles destinados a almacenes o bodegas que se benefician de los bajos costos de alquiler. Así mismo, cabe mencionar que existen diferentes patrones de obsolescencia: física, funcional y económica (Rojas, 2004). En el centro de Guayaquil la obsolescencia física y el estado de deterioro de las edificaciones y espacio físico 
conllevó a una obsolescencia funcional al observarse y comprobarse, por medio del registro de medidores de luz y del catastro municipal, el abandono de las edificaciones y la subutilización de los espacios como bodegas de materiales e inclusive lugares para la prostitución. Esta situación acarreó, a su vez, una obsolescencia económica, al reducirse la valoración de estos inmuebles y solares y el poco interés inmobiliario para implantar proyectos en el centro.

Siguiendo la tendencia implantada desde Europa y Estados Unidos (McCarthy, 1998), las ciudades en América Latina desde hace algunos años se han dedicado a la regeneración y reconversión de sus centros urbanos. En efecto, se han realizado diferentes experiencias en la región, especialmente en función de estrategias de desarrollo turístico (Scarpasi, 2005). Como las experiencias de Puerto Madero en Argentina o Malecón 2000 en Guayaquil, las que utilizaron al proyecto urbano como elemento interventor y dinamizador del espacio y economía urbana por medio de estrategias de intervención como en el caso del Centro Histórico de Quito (Azevedo, 2001).

Un efecto muchas veces no deseado de estos procesos de renovación y recuperación de áreas centrales es la gentrificación o aburguesamiento, como un fenómeno resultante en el cual las clases sociales de menores ingresos pueden verse desplazadas de su lugar de origen por efecto del incremento de los valores del suelo y de las nuevas dinámicas económicas-sociales-urbanas implantadas (Inzulza-Contardo, 2012; Lees \& Ley, 2008; López-Morales, 2013; Slater, 2006). Existen, sin embargo, formas de evitar este fenómeno, y una de ellas es la participación de la comunidad involucrada, como una vía de paliar los efectos adversos de un posible desplazamiento. Existen también diferentes instrumentos de gestión del suelo que pueden ayudar a evitar este fenómeno, como las zonas de inclusión, los fideicomisos comunitarios de tierra, instrumentos tributarios, derechos de desarrollo transferibles, solo por citar unos pocos o la creación de subsidios como en el Centro Histórico de Quito, donde se ha utilizado el componente de vivienda solidaria (Rojas, 2004), para diversificar la mezcla de actividades y la composición social del área recuperada, mitigando los efectos negativos del aburguesamiento que suelen acompañar la recuperación de áreas centrales deterioradas.

Sin embargo, el enfoque de trabajar con las fuerzas del mercado para promover la vivienda económica como parte integral del proceso de rehabilitación necesita la intervención del Estado para la generación de subsidios, así como también para que oficie como ente regulador que exija a los desarrolladores urbanos el cumplimiento de normas que den oportunidades para las familias de bajos ingresos, como condicionante para la aprobación de proyectos. De esta forma se puede crear una situación de ganancia-ganancia, en la cual el inversionista pueda lograr una utilidad atractiva $y$, al mismo tiempo, se posible asegurar la permanencia de las familias de menores ingresos que, de otro modo, se verían desplazadas. 


\section{La función social de la propiedad}

La función social de la propiedad es un concepto y principio legal que separa el derecho de propiedad del suelo de la potestad de edificar y es sobre la base de este enunciado que se fundamenta que la propiedad presenta caracteres colectivos (Neira, 2014). Dicha premisa se basa, a su vez, en los postulados de Henry George, filósofo de principios de siglo (Molinatti, 2013). Se trata de una concepción que ha evolucionado en el tiempo pues en un inicio en el contexto ecuatoriano, se consideraba que el derecho a la sociedad proveía al propietario de potestades absolutas sobre su terreno y sin bien existían leyes establecidas en la Ley de Régimen Municipal respecto del caso de Guayaquil, su implementación era escasa (Neira, 2014). A su vez, la función social de la propiedad se basa en los principios de solidaridad y equidad social establecidos en la Constitución ecuatoriana a partir del año 2008 (Neira, 2014). La separación entre el derecho a la propiedad del suelo y la facultad de edificar se hace todavía más evidente en el Proyecto de Ley de Ordenamiento Territorial del Ecuador establecido en el año 2010 por la Asamblea del Ecuador, art. 47, sobre el incumplimiento del deber de edificar que establece un impuesto del dos por mil a solares no edificados y art. 49 sobre la expropiación en caso de incumplimiento de la función social de la propiedad, según datos aportados por el Código Orgánico de Ordenamiento Territorial Autónomo Descentralizado, COOTAD (2010) en su Borrador Proyecto de Ley Orgánica de Ordenamiento Territorial y Gestión del Suelo.

Sin embargo, la función social de la propiedad como principio ya había sido incluida en los planes de ordenamiento de Guayaquil, como en la Ley Orgánica de Régimen Municipal (LORM) de 2005, la cual hacía referencia a la obligación de construir, la imposición de recargos tributarios a los solares vacíos, así como la expropiación por el incumplimiento de la obligación de construir. El destino de los predios expropiados sería para vivienda social, si bien esto dependía de la zonificación asignada al área y de la disponibilidad de recursos. Del mismo modo, esta ley otorgaba a los municipios la potestad de imponer una asociación forzosa a propietarios de terrenos, con el fin de hacerlos partícipes del reparto de cargos y beneficios del proceso de urbanización. Sin embargo, esta ley no fue eficaz para la regulación y control del desarrollo urbano e inmobiliario de Guayaquil, debido a su falta de aplicación e implementación (Neira, 2014) y por ser básicamente el mismo cuerpo legal que entró en vigencia en 1966. De esta forma, el uso de una normativa municipal que permaneció inalterada por un periodo de 39 años, tiempo en el que la ciudad experimentó un incremento de su población de un $800 \%$, esto es, de 510.000 habitantes en 1962 según datos aportados por el INEC (2011) aumentó a 2.226 .557 en 2005, según datos proporcionados por el M.I. Municipalidad de Guayaquil (Sánchez, 2014) y de su trama urbana de 2.200 hectáreas en 1962 se convirtió en 26.974 hectáreas en 2005 (Sánchez, 2014); todo ello permite suponer su ineficacia como instrumento de regulación y 
control de dicho crecimiento. Adicionalmente, esta ley presentaba numerosos vicios de redacción legislativa con términos imprecisos que fomentaban la discrecionalidad de funcionarios públicos (Neira, 2014), y que favorecían múltiples interpretaciones administrativas y judiciales. Como por ejemplo la redacción del artículo 320 que define la obligación de construir solo para "terrenos de mayor superficie en áreas urbanas donde se pudiera construir" (LORM). Estas indefiniciones propiciaron un amplio campo para la interpretación en la aplicación de estas leyes, que se refleja en la ineficiencia como organismo de regulación y control del desarrollo urbano de Guayaquil.

\section{El derecho a la ciudad}

El carácter colectivo de la función social de la propiedad y los derechos colectivos que esta conlleva se fundamentan en las propuestas políticas y epistemológicas de Henri Lefebvre (Gasic, Narvaez y Quiroz, 2015; Lefebvre, 1970), según las cuales este derecho involucra la potestad de la apropiación colectiva en términos de uso y disfrute de los espacios públicos por la ciudadanía en general; y la participación en el proceso de toma de decisiones en la producción social del espacio (Harvey, 2013).

Respecto del contexto ecuatoriano, el ejercicio del derecho a la ciudad rebasa la visión tradicional del Código Civil ecuatoriano -que data del año 1861-y de otros conceptos clásicos de propiedad y acceso al suelo, expresados en la Constitución de septiembre del 2008, que reemplaza a la anterior de 1998, enmarcada en los principios del Buen Vivir (sumak kawsay, en quechua) como objetivo principal del actual Gobierno ecuatoriano.

Así, según el artículo 31 de la Constitución del Ecuador, se establece que "las personas tienen derecho al disfrute pleno de la ciudad y de sus espacios públicos, bajo los principios de sustentabilidad, justicia social, respeto a las diferentes culturas urbanas y equilibrio entre lo urbano y lo rural" (Asamblea Constituyente de Ecuador, 2008). Este derecho se reafirma en la recientemente aprobada Ley Orgánica de Ordenamiento Territorial, Uso y Gestión del Suelo, por la Asamblea Nacional en julio 2016 (Ley Organica de Ordenamiento Territorial y Gestion del Suelo, LOOTUGS, 2016), artículo 6, capítulo II, como principio rector y orientador del ordenamiento territorial.

De esta forma, la visión humanista de Lefebvre se reivindica en un mundo que ya es otro y en un contexto como Ecuador y la ciudad de Guayaquil específicamente, pero que necesita más que nunca de sus postulados, aun cuando para su implementación se requiere mayor precisión y argumentación, debido a las condiciones urbanas actuales, como el crecimiento de la trama urbana, el aumento de las desigualdades, el uso intensivo del automóvil, la edificación de muros y privatización de espacios públicos. Así, el derecho a la ciudad reivindica sobre todo el derecho a la vivienda y a la localización de esta 
y, como tal, el derecho a los ciudadanos a no ser desalojados de su hábitat urbano, para poder ser partícipes de los procesos de renovación. Es necesario, por tanto, encontrar mecanismos e instrumentos de gestión territorial que permitan el ejercicio de este derecho. En este sentido, resulta clave el rol que pueda desempeñar el Estado, como ente regulador de las políticas de acceso al suelo y del mercado, con el fin de promover el derecho a la ciudad y a la vivienda de los sectores más vulnerables (Bagnera, 2016).

\section{Recuperación de plusvalías}

La recuperación de plusvalías se refiere al proceso por el cual el sector público obtiene total o parcialmente los incrementos del valor del suelo "creados socialmente" o comunalmente más que por la acción individual de los propietarios (Smolka, 2013). Ecuador, así como la mayoría de países latinoamericanos, se caracteriza por sus enormes desigualdades sociales, especialmente en el acceso a infraestructura básica, aun cuando ha existido un mejoramiento en los últimos años. Así, en el 2001 el abastecimiento de agua en la vivienda era de $67,5 \%$ y subió a $82,2 \%$ en 2010 ; en cuanto al acceso al sistema eléctrico este se incrementó de $89,7 \%$ a $92 \%$; la eliminación de aguas servidas aumentó de un $48 \%$ a un $85,1 \%$, siendo este el cambio más notable en cuanto a accesibilidad a servicios básicos; la eliminación de basura en la vivienda cambió de $62,7 \%$ a $79,5 \%$ y por último el servicio telefónico en la vivienda se incrementó de 32,2\% en 2001 a 76,3\% en 2011 (INEC, 2011).

Estas desigualdades son generadas por las dinámicas de mercado por medio de las cuales se incrementan los valores de la tierra y sus precios. Henry George, economista de fines del siglo pasado, ya promulgaba la creación de un impuesto para redistribuir los incrementos de valor de la tierra a la comunidad (Furtado y Acosta, 2012). La recuperación de plusvalías se presenta como una alternativa para el financiamiento del desarrollo urbano y vivienda social. Sin embargo, es esencial recalcar que estos instrumentos no deberían ser utilizados como un impuesto de utilidad para todas las transferencias de dominio. Es decir, las recuperaciones de plusvalías deben estar articuladas con una gestión territorial y para ciertos sectores definidos en un plan específico de ordenamiento (Smolka, 2013). En este artículo se hace énfasis en una movilización de plusvalías, lo que significa no solo recuperar el valor de un bien inmueble independientemente del destino que puedan tener los fondos recuperados, sino utilizar esos fondos para financiar obras públicas o sociales que sean capaces de movilizar la renta urbana con un sentido de justicia social.

A partir de este punto se genera la hipótesis del presente estudio, esto es, que a través de la utilización y aplicación de instrumentos de gestión del desarrollo urbano, se podrá crear un ambiente urbano renovado y diversificado que promoverá la atracción de inversiones y recuperación de capitales en el área, 
al mismo tiempo que asegurará la permanencia e inclusión de vivienda social en el centro.

\section{El centro de Guayaquil}

Breve historia del centro de Guayaquil. Desde el siglo XVII se empieza a dividir la ciudad de Guayaquil en dos: Ciudad Vieja y Ciudad Nueva (Laviana, 2008). La primera se inicia con un trazado ortogonal, con una plaza central, centro de la administración pública y lugar de residencia de los grupos acomodados y, la segunda, con un trazado irregular donde residían las clases sociales de menores recursos (Figura 1 ).

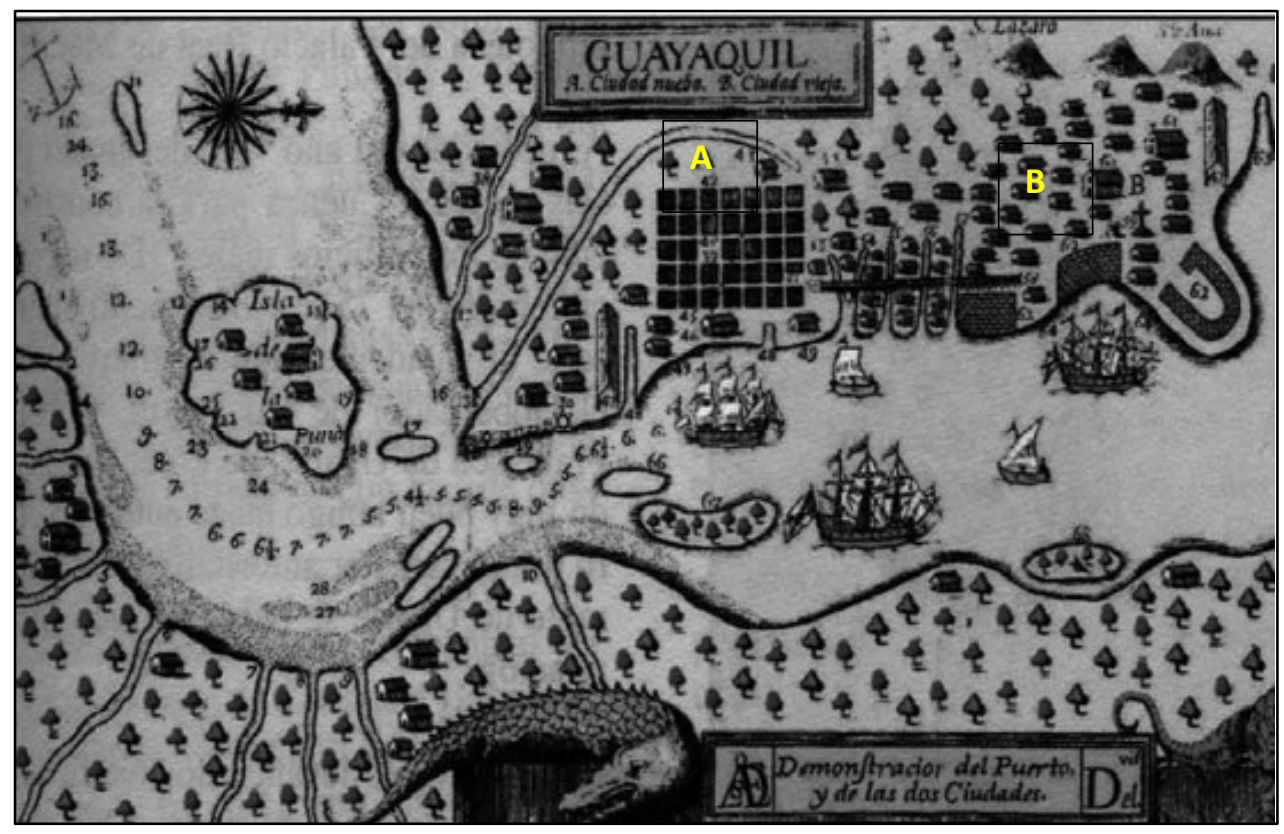

Figura 1. Mapa histórico de Guayaquil.

Nota: A: Ciudad Vieja; B: Ciudad Nueva.

Fuente: Archivo histórico del Guayas.

Las viviendas de las elites locales estaban ubicadas a lo largo del Malecón sobre el río Guayas, y eran de dos pisos: en la planta alta residían las clases altas, mientras que la planta baja se destinaba a locales comerciales (Allan, 2010). A raíz del boom del cacao (1880), Ecuador llegó a ser el líder mundial exportador de este producto, generando alrededor del 20 al $25 \%$ de la producción total mundial. Movimientos migratorios provenientes de otras ciudades del país y del exterior comenzaron a arribar a la ciudad, ubicándose 
inicialmente en el centro en unidades habitacionales conocidas como tugurios ${ }^{2}$ y luego ubicándose al sur en los denominados suburbios y guasmos (Delgado, 2013).

Posteriormente, con el boom del banano en 1950, el Ecuador se transformó en exportador mundial. En Guayaquil los primeros edificios de altura empezaron a aparecer en el centro de la ciudad y se inició un proceso de deterioro del espacio urbano, que se agudizó más con la nueva localización del puerto al sur de la ciudad en 1960 (Gonzales, 2003). La crisis bananera trajo más movimientos migratorios a la ciudad: en 1968 la mitad de la población vivía ya en las zonas periféricas, en los suburbios, al sur. La ciudad continuó expandiéndose hacia las zonas del norte a lo largo de las vías de acceso, como la vía a la Costa, vía a Daule, y la vía Perimetral, creándose grandes zonas de asentamientos informales fuera de los límites urbanos, como Prosperina, Mapasingue, Fortín, Flor de Bastión, Balerio Estacio, Paraíso de la Flor, Horizontes del Guerrero, y Monte Sinaí, entre otros (Sánchez, 2014).

En los años 80, la baja del petróleo ocasionó un estancamiento y crisis económica. La ciudad entró en un periodo de decadencia y deterioro de sus espacios públicos y servicios. En el periodo de 1985 a 1990 la calidad del espacio público disminuyó, el caos vehicular y la falta de lugares de parqueo se sumó a la presencia masiva de comerciantes informales en algunas calles del centro. La infraestructura vial sufrió deterioro; así como también la fachada de edificaciones. Masas de cables cruzaban las calles, contribuyendo al caos visual del espacio urbano (Delgado, 2013). Los grupos sociales de altos y medianos ingresos se trasladaban al norte de la ciudad, a las primeras urbanizaciones cerradas. Los procesos de expansión formal en la periferia, específicamente de nuevos proyectos de vivienda social, se generaron sin considerar los costos en infraestructura que se impondrían a la administración local, junto con preferencias de la población ${ }^{3}$. De esta forma, el centro perdía su carácter multifuncional como lugar para la recreación, producción, comercio y vivienda y se convertía, exclusivamente, en lugar para transacciones comerciales. El Malecón de la ciudad degeneró de un área recreativa para el disfrute de ciudadanos y visitantes a un área insegura, y deteriorada. Así, en 1992 el índice de áreas verdes equivalía a $1 \mathrm{~m}^{2}$ por persona (Municipalidad de Guayaquil-MG, 2005). Todos estos factores, junto con la criminalidad existente, corrupción y deficientes administraciones municipales, llevó a la ciudad a un estado de estancamiento económico y devaluación de valores de bienes muebles e inmuebles del centro (Delgado, 2013).

\footnotetext{
${ }^{2}$ Espacios de habitación en el centro de la ciudad, como resultado de la subdivisión de lotes y espacios en las viviendas, muchos de ellos en estado precario y carente del espacio mínimo habitable y de las condiciones básicas de salubridad y habitabilidad.

${ }^{3}$ Según un estudio realizado en el caso de Guayaquil el $95 \%$ prefiere vivir en viviendas aisladas que en departamentos y fuera del centro de la ciudad (Delgado \& De Troyer, 2011; Delgado y De Troyer, 2016).
} 


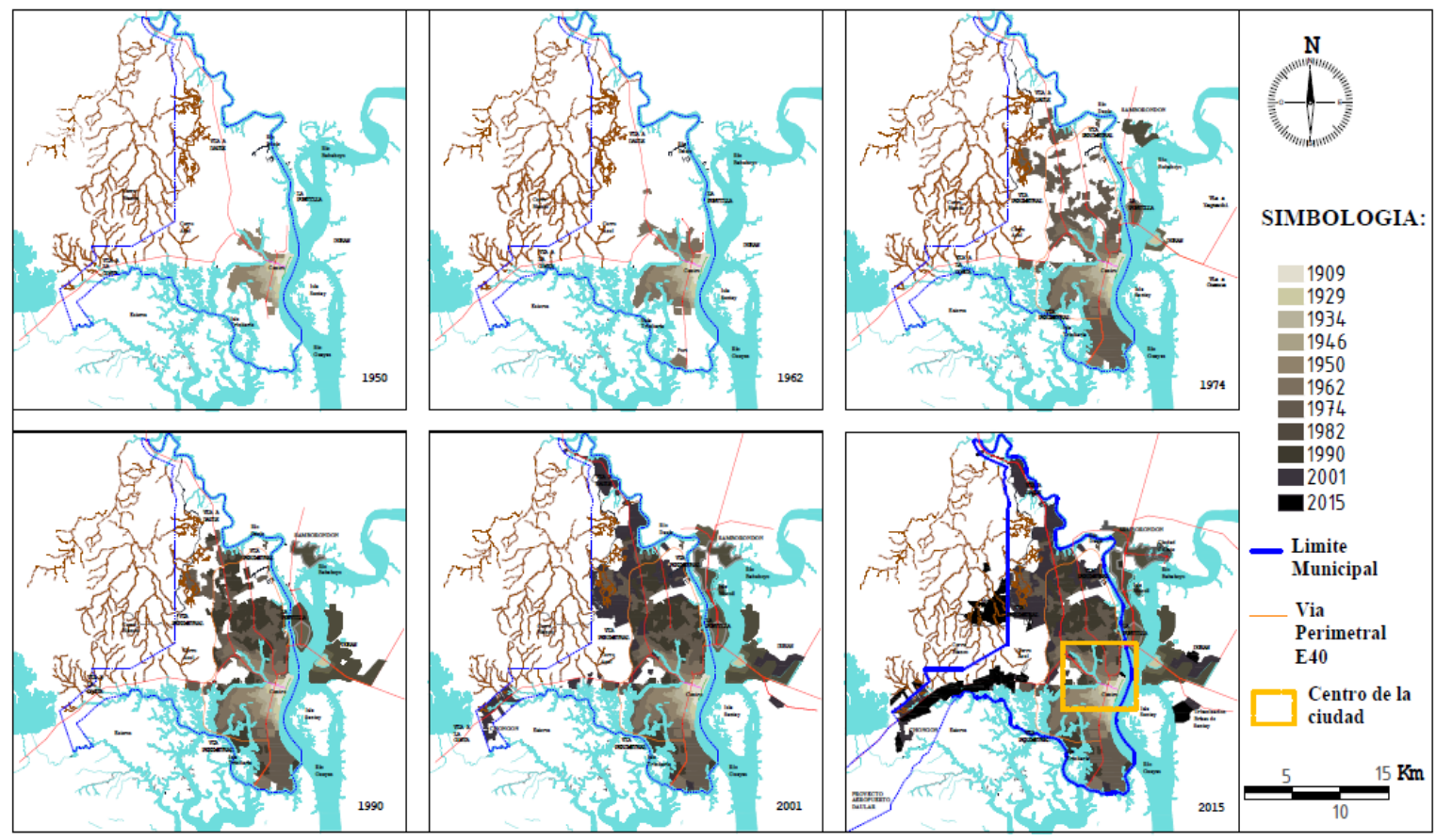

Figura 2. Mapa del desarrollo histórico urbano de Guayaquil.

Fuente: Editado por autor sobre la base de Delgado, 2013.

En medio de este contexto la banca privada, con ocasión del Aniversario 75 del Banco La Previsora, tomó la iniciativa de invitar a un grupo de expertos de la Universidad de Oxford Brooks, Inglaterra, para desarrollar una propuesta urbana de regeneración del Malecón de la ciudad, con el fin de atraer inversiones y turismo al centro de Guayaquil por medio de la creación de zonas comerciales, culturales, parqueos e incrementando las áreas verdes y de recreación (Delgado, 2013). Esta iniciativa, además de cumplir con el objetivo cívico, tuvo como finalidad revalorizar el edificio del Banco La Previsora ${ }^{4}$, que junto con otras propiedades del centro, se estaba desvalorizado como consecuencia del deterioro urbano anteriormente relatado. La propuesta fue presentada al alcalde en ese tiempo, el Ing. León Febres Cordero, quien apoyó la iniciativa, así como también por las más importantes organizaciones cívicas, empresariales, sociales y académicas de la ciudad. Se desarrolló una visión de proyecto en la cual el proyecto "Malecón 2000" actuaría como catalizador y generador de posteriores proyectos en el centro de la ciudad (Wong, 2005).

\footnotetext{
${ }^{4}$ La Previsora es un edificio de 33 pisos construido a principios de los años 90 y localizado frente al Malecón en el centro de la ciudad.
} 
El proyecto "Malecón 2000" está ubicado a lo largo de la Avenida Simón Bolívar, frente al río Guayas, en el malecón de la ciudad y tiene una extensión de 2,5 km (ver Figura 3). La "Fundación Malecón 2000" se encargaría de su diseño, construcción, dirección y mantenimiento. Adicionalmente, la Municipalidad cedió los terrenos donde se implantaría el proyecto en comodato a la Fundación Malecón 2000 durante 100 años y se promulgaron leyes especiales a nivel nacional que permitieron que los contribuyentes donaran voluntariamente el $25 \%$ del impuesto a la renta para el financiamiento y construcción del proyecto.

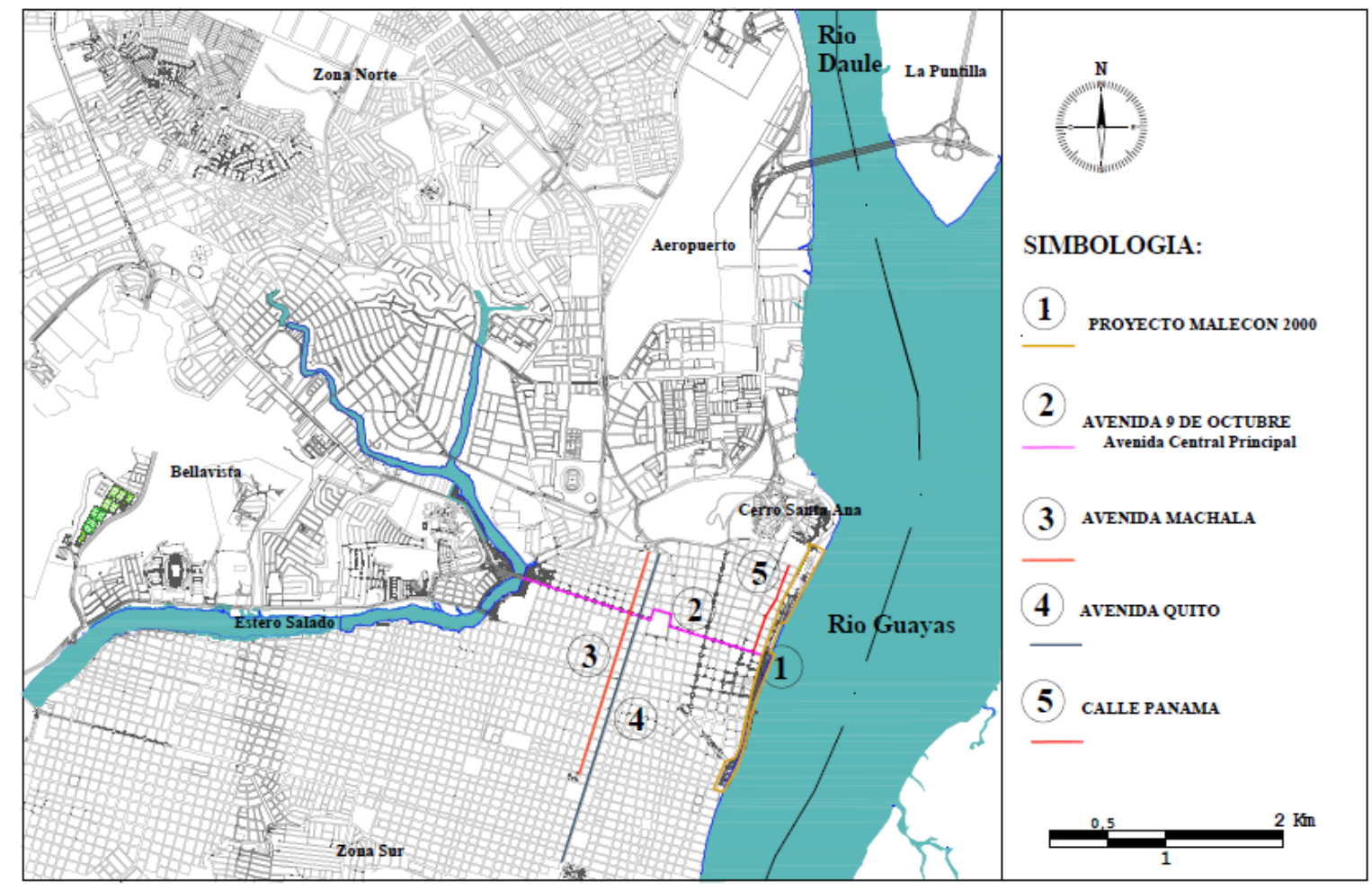

Figura 3. Mapa del centro de Guayaquil, ubicación avenidas principales y proyecto Malecón 2000.

Fuente: Adaptado por autor sobre la base de planos de la Municipalidad de Guayaquil.

Nota: El Proyecto Malecón 2000 (1), se conecta con el Estero Salado por medio de la Av. 9 de octubre (2), principal axis de la ciudad. Perpendicular a este, las avenidas Machala (3) y Quito (4) conectan el norte y sur de la ciudad. Adicional y paralelo al Malecón se encuentra la Avenida Panamá (5) reconocida por su valor histórico-comercial.

Complementariamente crearon zonas de parqueos y comerciales que iban a sustentar económicamente el mantenimiento del proyecto y áreas públicas como plazas y jardines. El proyecto Malecón 2000 fue concebido como agente revitalizador del área central de la ciudad contigua al malecón del río Guayas y 
como generador de futuros proyectos. Respecto de esto último, el impacto del proyecto ha sido controversial. Así, algunos críticos consideran que el proyecto contribuyó a generar exclusión de grupos de comerciantes informales, imposición de reglas en el uso de este espacio público (Andrade, 2007a; 2007b; Swanson, 2007) y segregación espacial (Moser, 2009); además de no contribuir a promover proyectos de vivienda social o mejoramiento de infraestructura en el centro o en otras áreas de la ciudad (Verrewaere \& Wellens, 2010). De forma adicional, a partir de este proyecto se generó el desarrollo inmobiliario "Puerto Santa Ana", al extremo norte, criticado por su carácter elitista dirigido en un $80 \%$ a viviendas y oficinas de las clases sociales de mayores ingresos y solo un $20 \%$ del área destinada para espacios públicos (Delgado, 2013).

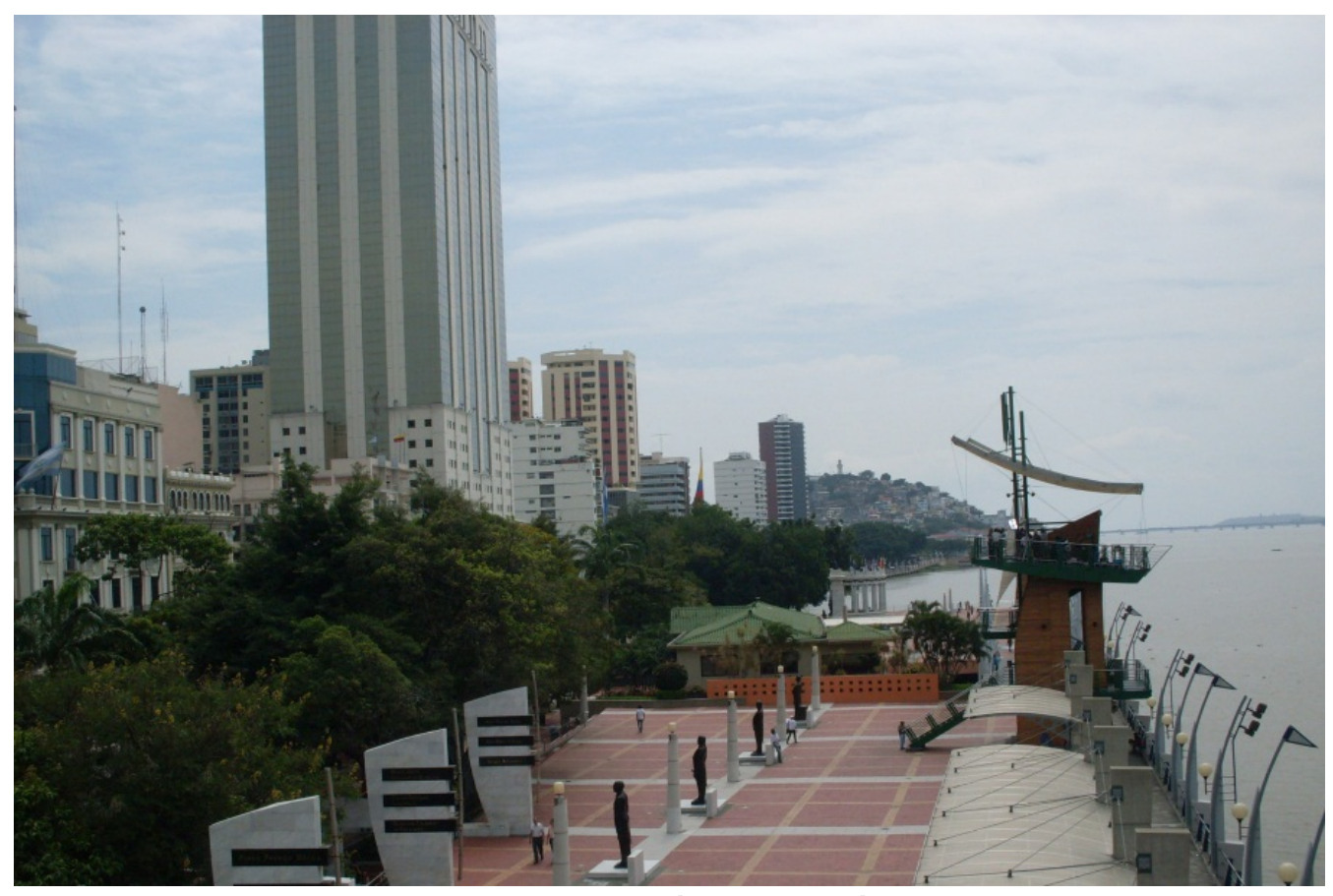

Figura 4. Proyecto Malecón 2000, área central.

Fuente: Delgado 2013.

Nota: La edificación predominante al lado izquierdo de la foto corresponde al edificio del Banco La Previsora, entidad promotora del proyecto junto con la Municipalidad de Guayaquil. Al fondo el cerro Santa Ana, lugar de fundación histórica de la ciudad y a la derecha el río Guayas.

Propuestas urbanas a implementar. Después del proyecto Malecón 2000, la municipalidad no ha podido realizar otro proyecto de similares dimensiones y envergadura en el entorno urbano-económico del centro. Por tanto, planteó con ocasión de celebrar el Bicentenario de la ciudad en el año 2024, la implementación de proyectos para su renovación, como la rehabilitación del eje vial Machala-Quito. Con este objetivo, la Dirección de 
Promoción Ciudadana del diario El Expreso por pedido de la M.I. Municipalidad de Guayaquil, invitó a la ciudadanía a participar con propuestas destinadas al rescate urbanístico dicho eje, el cual es uno de los más importantes de la ciudad, que parte desde el Puerto Marítimo en el sur, hasta el aeropuerto José Joaquín de Olmedo, terminal terrestre Jaime Roldós Aguilera, y el puente de la Unidad Nacional, en el norte. Sus siete carriles de ancho en cada avenida, a lo largo de sus casi $3 \mathrm{~km}$, conectan en su recorrido centros de artes, escenarios deportivos, colegios emblemáticos, hospitales, mercados artesanales, iglesias y templos, parques y plazas, instituciones públicas y privadas, tales como el Consejo de la Judicatura, la Casa de la Cultura, el Ministerio de lo Laboral, y la Cruz Roja.

Sin embargo, a pesar de ser un eje vial estratégico, muestra áreas con usos de suelo no compatibles, es decir, comercios de venta de materiales de construcción al granel (piedra, cemento, arena) junto con edificios vetustos de vivienda y terrenos no utilizados o subutilizados; "hoteles" donde es práctica común la prostitución y comercios de todo tipo, cinco gasolineras, ausencia de áreas verdes y espacios deprimidos (infraestructura de veredas y bordillos destruidos y sucios, portales donde pernoctan mendigos), que dan una impresión de desorden, descuido y abandono, llegando a ser inclusive considerada zona roja por su alta peligrosidad delincuencial, especialmente en la noche, además del caos peatonal y vehicular. Para ilustrar la subutilización y basándonos en datos del uso de medidores de proporcionados por la Empresa Eléctrica a febrero 2015 de 740 edificaciones del área un 9\% registran un consumo de cero y un $33,38 \%$ un consumo menor de $40 \mathrm{kWh}$, reflejando la no utilización y subutilización de las edificaciones.

El taller de diseño urbano de la Facultad de Arquitectura e Ingeniería de la Universidad de Especialidades Espíritu Santo de Guayaquil, en respuesta a la invitación planteada, realizó una propuesta conceptual de anteproyecto de creación de un corredor urbano (ver Figuras 5 y 6), con la inclusión de un área verde central, ordenación del uso del suelo para vivienda, oficinas públicas y privadas, hoteles y restaurantes, centros comerciales, áreas de parqueos, pasos peatonales elevados, una ciclovía y paso elevado peatonal que recorre las manzanas centrales que serían reservadas para áreas verdes y recreacionales, donde se encuentran edificaciones patrimoniales como la iglesia Nuestra Señora del Carmen, el Parque la Victoria y el Mercado Artesanal, además de edificios destinados a la cultura y funciones públicas; así como el desarrollo de espacios vacíos o subutilizados. Se dividió al sector en uno sector central entre las calles Luque-Clemente Ballen y Ayacucho, para edificaciones patrimoniales, culturales y comercio artesanal; y un sector sur entre el colegio Guayaquil y Ayacucho donde se reutilizaría la mayoría de solares vacíos y edificaciones para vivienda social y reubicación de habitantes del sector y de otras zonas de la ciudad. 
Se consideró la utilización de los solares y edificaciones en desuso para destinarlos para vivienda social (22 solares vacíos en los sectores que comprende el área entre las calles Quito y Machala, con un área promedio de estos lotes de $480 \mathrm{~m}^{2}$ ), lo que permitiría incluir seis departamentos de $70 \mathrm{~m}^{2}$ por piso y cuatro en planta baja, generándose un total por edificación de 28 departamentos, lo que estimado por los 22 solares disponibles resultaría en 616 departamentos que se podrían construir en los solares actualmente vacíos entre las avenidas Quito-Machala.

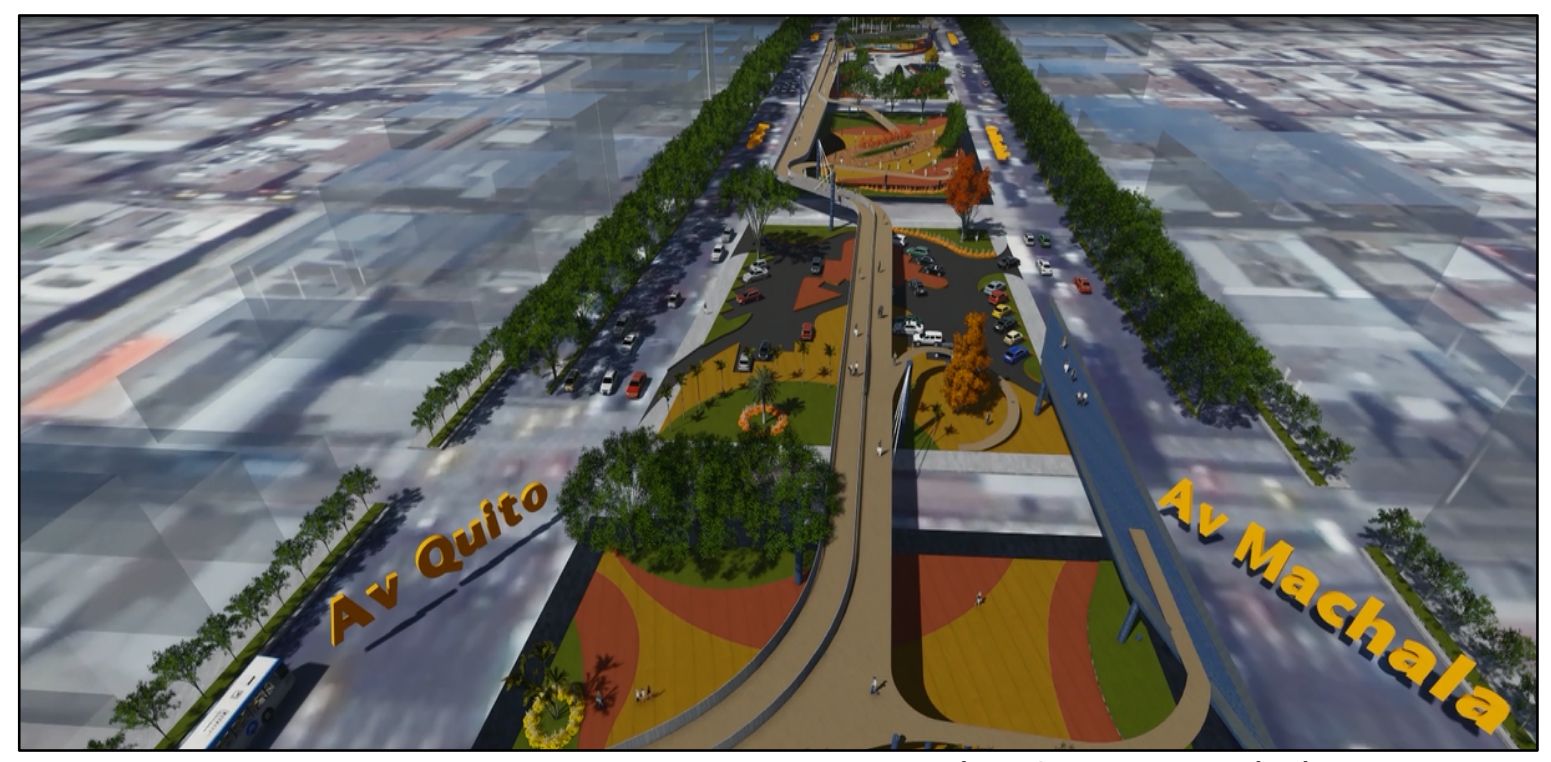

Figura 5. Proyecto Bicentenario Avenidas Quito y Machala.

Fuente: UEES-Perfil del Proyecto Bicentenario, 2015. 


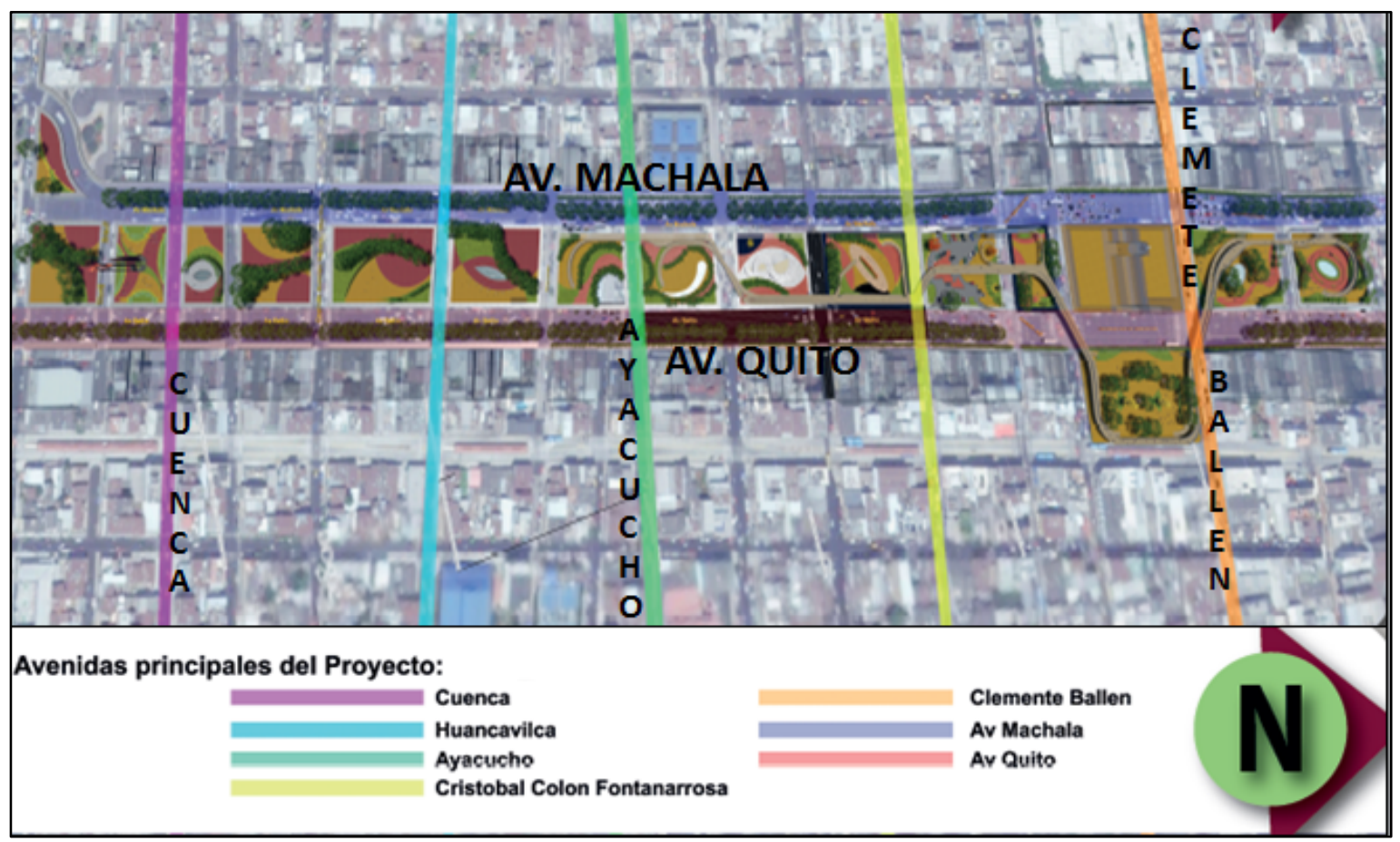

Figura 6. Proyecto Bicentenario Avenidas Quito y Machala-Avenidas Principales. Fuente: UEES-Perfil del Proyecto Bicentenario, 2015.

Se consideró para el análisis de este artículo esta última propuesta, debido a que promueve una revisión crítica y discusión en torno a cuáles instrumentos de gestión urbana y financiamiento del desarrollo pudieran ser aplicados al contexto de Guayaquil y a este proyecto en particular, para la valorización y desarrollo del centro. A continuación se revisarán los principales instrumentos de gestión que, de acuerdo con las condicionantes del contexto de Guayaquil y del país, pueden ser aplicadas para el financiamiento de vivienda social e infraestructura.

\section{Instrumentos de gestión y financiamiento del desarrollo urbano}

Dentro del contexto urbano y de las propuestas antes mencionadas, los diferentes instrumentos de gestión del desarrollo urbano se convierten de esta manera, en el vehículo para "capturar el valor" ${ }^{5}$ (Smolka, 2013, p. 10) de la operación urbana, para el financiamiento de obras y vivienda, sin que esto implique procesos de gentrificación que excluyan a las familias de menores recursos del sector. Los instrumentos de gestión del suelo se clasifican en:

- instrumentos para la distribución equitativa de cargas y beneficios a través de la planificación de unidades urbanísticas;

\footnotetext{
${ }^{5}$ Recuperación del valor del suelo (ganancias inmerecidas o plusvalías) generados por acciones diferentes a la acción directa del propietario (Smolka, 2013).
} 
- instrumentos en cuanto a la intervención de la morfología urbana y estructura predial;

- instrumentos para regular el mercado del suelo;

- instrumentos para el financiamiento del desarrollo urbano; e

- instrumentos para la gestión del suelo de asentamientos de hecho (Asamblea del Ecuador, 2016).

La recientemente aprobada Ley Orgánica de Ordenamiento Territorial, Uso y Gestión del Suelo en el Ecuador (LOOTUGS) da el marco legal donde se hacen explícitos el derecho a la ciudad y a la vivienda, así como también los diferentes instrumentos de gestión urbana.

A continuación se mencionan aquellos instrumentos de los que existe ya alguna experiencia previa en el contexto ecuatoriano $y$, a su vez, aquellos que presentan potencial para la financiación de infraestructura, obras y vivienda social aplicados al centro de la ciudad. Respecto de los instrumentos para intervenir la morfología urbana y estructura predial como reajuste de terrenos, en el caso de Guayaquil este instrumento se aplica actualmente más para las zonas construidas del centro, que para la periferia y las zonas de expansión al noroeste de la ciudad.

Seguidamente, acerca de los instrumentos que se pueden utilizar para regular el mercado del suelo, está el crear zonas especiales de interés social de tal forma que, independientemente, del incremento del valor del suelo como resultado de proyectos de regeneración urbana, se destinen zonas especiales para vivienda social por medio de la zonificación a través de normas, como una forma de conservar a los moradores en sus lugares originales y evitar la exclusión social (Smolka, 2013). En el caso de Guayaquil, dentro del centro se pueden declarar zonas prioritarias para el desarrollo de vivienda social, como a los lados de las Avenidas Quito y Machala, específicamente en el sector sur de esta. De esta forma, sin importar cuál sea el incremento de valor de estos lotes debido a la regeneración urbana a consecuencia del proyecto, por medio de la norma sea posible conservar la vivienda social en el centro.

Adicionalmente, entre los instrumentos de gestión para financiar el desarrollo urbano que se pudieran aplicar al caso del centro Guayaquil, uno de ellos es la venta de derechos de edificación, que se basa en la separación del derecho de la propiedad y el derecho a edificar (Sandroni, 2011) y que establece coeficientes de edificación mínimos (esto es, el porcentaje mínimo de utilización de un lote para que cumpla su función social), básicos (que es la superficie que todo propietario tiene derecho a desarrollar) y máximos (que es la cantidad de desarrollo permitida por la infraestructura existente y las normas de edificación). Los ingresos generados por la venta de derechos de edificación en el centro de Guayaquil como resultado de proyectos urbanos servirían para financiar vivienda social e infraestructura dentro de la misma 
zona central. Existen también otros instrumentos considerados en la ley que también se podrían usar para la regulación del mercado del suelo en el centro de la ciudad como: el derecho de adquisición preferente, la declaración de desarrollo y construcción prioritarias, y el anuncio de proyecto (Asamblea del Ecuador, 2016).

Además, existen experiencias de instrumentos para financiar el desarrollo urbano en otros contextos de ciudades y países (Furtado y Acosta, 2012) y que se podrían aplicar al caso de Guayaquil aun cuando no están todavía explícitamente mencionados en el marco jurídico del LOOTUGS: uno de ellos es el uso de bonos de densidad (Molinatti, 2013), que contempla el otorgamiento de derechos, permisos de construcción y/o beneficios normativos a cambio de destinar un porcentaje de los proyectos para beneficio público de la comunidad, como podría ser vivienda social o infraestructura. Sin embargo, el uso de bonos de densidad, así como también la venta de derechos de edificación, deben basarse en un análisis acerca de la capacidad de las instalaciones públicas y de la infraestructura del centro de la ciudad y en un plan regulatorio y de inversiones (Calavita y Mallach, 2009); de tal forma que los niveles de los servicios prestados y la calidad de vida del sector, en este caso el centro de Guayaquil, no se vea disminuida por un uso excesivo de estos instrumentos. Los bonos de densidad, a su vez, pueden servir para financiar los programas de vivienda inclusiva (Calavita y Mallach, 2009, los cuales son regulaciones de uso de suelo que obligan a los desarrolladores residenciales privados a destinar un porcentaje de sus unidades (entre un 10\% y un 20\%) para vivienda social. Si bien, para este tipo de instrumentos no existe todavía una legislación local, las características del contexto permiten asumir su posible aplicación, como la descentralización fiscal existente, junto con una mayor independencia fiscal municipal, el cambio de énfasis de una planificación enfocada a nivel de ciudad a una que se basa más en proyectos y áreas específicas (Smolka, 2013), y un incremento en la conciencia social y redistribución de recursos enmarcada en la política actual del gobierno central ecuatoriano.

También respecto de los lotes subutilizados u ociosos en el centro de la ciudad estos, al no cumplir la función social de la propiedad, estarían sujetos a sanciones por medio de un impuesto que se distinguiría del impuesto predial por su carácter extrafiscal y como un medio para inducir al propietario a dar al predio el uso al que estaba destinado (Furtado y Acosta, 2012). En el Ecuador, el Código Orgánico de Organización Territorial y Autonomía Descentralizada COOTAD, capítulo III, establece en el artículo 507 un impuesto del 2 por mil a inmuebles no edificados ubicados en zonas urbanas dotadas de servicios básicos.

Por su parte, en Guayaquil la aplicación de instrumentos para la gestión del suelo es todavía bastante incipiente y se utilizan principalmente instrumentos 
tributarios, pero sin una norma que canalice su aplicación para vivienda social o desarrollo urbano social prioritario. Uno de los que se ha utilizado es la contribución por mejoras, para el financiamiento de infraestructura urbana como puentes y que se cobra a través de los impuestos prediales. Importantes proyectos para la zona de conurbación urbana de la ciudad, (GuayaquilSamborondon y el proyecto del puente sobre el río Daule) estarán financiados de esta forma. Respecto de este proyecto se debería proponer que los fondos que se recauden sirvan también para financiar vivienda social para la ciudad en general y el centro, así como para la generación y mantenimiento de áreas verdes y parques.

La aplicación de este instrumento en las zonas del centro debería ser en el marco de una política destinada a fomentar la dotación de vivienda social, de tal forma que no se convierta en un mecanismo que sirva para el efecto contrario al que se busca y provoque la expulsión de la población que no pueda pagar el incremento de los valores del suelo. En el Ecuador la contribución de mejoras está normada a través del COOTAD, capítulo $\mathrm{V}$ y el cobro, artículo 592, depende de la emisión de una ordenanza por cada gobierno seccional.

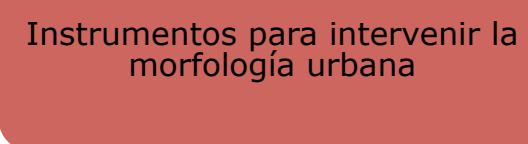

Instrumentos para regular el mercado del suelo
- Reajuste de terrenos

-Integración inmobiliaria

-Cooperación entre partícipes
Instrumentos para financiar el desarrollo urbano
- Creación de zonas especiales de interés social -Derecho de adquisición preferente

- Declaración de desarrollo y construcción prioritarias -Anuncio de proyecto

-Bancos de suelo

- Concesión onerosa de derechos

-Venta de derechos de edificación

- Bonos de densidad

-Contribución por mejoras

Figura 7. Principales instrumentos aplicados y propuestos para la gestión y financiamiento del desarrollo urbano del centro de la ciudad de Guayaquil. Fuente: Elaborado por el autor sobre la base a LOOTUGS, 2016. 


\section{La multiplicidad de visiones de la ciudad diversa}

Además de la aplicación de los diferentes instrumentos para el financiamiento de obras y vivienda social, es necesario reevaluar la multiplicidad de visiones respecto de los proyectos de rehabilitación urbana en el centro y la creencia de que los desarrollos de vivienda social son incompatibles con proyectos de renovación y que podrían ahuyentar las inversiones en los centros (Rojas, 2004). En relación con uno de estos grupos, los moradores de las clases altas, la reticencia de estos de integrarse a vivir en el centro en un ambiente con viviendas para personas de menores recursos se debe, en buena parte, a la identificación de estos como parte de la cultura popular, y de la cual suelen distanciarse las clases acomodadas (Espino, 2007). Sin embargo, es precisamente esta cultura popular lo que puede propiciar la revitalización de los centros y convertirse en el detonante del desarrollo económico y social, al fomentar el flujo de actividades, diurnas y nocturnas. Adicionalmente, existe el temor entre las clases altas de una disminución del valor de sus propiedades al considerarse esta integración de clases. Sin embargo, como plantea Sabatini et al. (2012) "probablemente las personas estarían más dispuestas a vivir con personas de otras clases sociales si esto también involucrara un mejoramiento de otros atributos como cercanía a los lugares que frecuentan, belleza del sector, equipamientos, etc." (p. 180).

Así mismo, los residentes de los apartamentos de vivienda social serían familias que han residido en la zona por muchos años. Es decir, se plantearían programas de permanencia de moradores originales que serían reubicados en apartamentos renovados dentro de la misma área de las avenidas estudiadas. Posteriormente, con el mejoramiento de la infraestructura, nuevos proyectos aparecerían y de esta manera la vivienda social se convertiría en el tipo de proyecto catalizador de inversiones y de recuperación de costos en el centro. De esta forma, para las familias residentes, la posibilidad de continuar viviendo en la misma área, manteniendo sus redes sociales y de trabajo por medio de la conservación de sus pequeños negocios, les permitiría conservar su identidad y contribuir a su bienestar y desarrollo personal (Espino, 2007). Al mismo tiempo, los horarios de atención extendida de estos negocios los convierte en centros de interacción social, contribuyendo a la seguridad del barrio.

En relación con los costos de desarrollos de proyectos de vivienda social en el centro y en la periferia de Guayaquil no es sencillo establecer una comparación, pues depende de las características de estos proyectos y es necesario tomar en cuenta algunos aspectos como la diversidad en el estado y materiales de las edificaciones, así como también la calidad de la infraestructura y servicios, lo que tanto en la periferia como en el centro puede variar considerablemente. Además, en proyectos en la periferia es posible considerar un componente de autoconstrucción que permite ahorrar costos y que no es factible de incorporar en proyectos en el centro. Por su parte, en el 
centro de la urbe podrían existir ahorros en transporte para los moradores que tengan en la zona su lugar de trabajo. A manera de ejemplo, se puede citar el proyecto habitacional "Mi Lote 2" ubicado en la periferia de la ciudad, en el cual el costo de una vivienda de $53 \mathrm{~m}^{2}$ es de $\$ 20.000^{6}\left(\$ 377 / \mathrm{m}^{2}\right)$ y con respecto al centro de la ciudad, los costos de renovación para una unidad habitacional de apartamento en una edificación de materiales mixtos de $45 \mathrm{~m}^{2}$ son de $\$ 25.600$, $\left(\$ 569 / \mathrm{m}^{2}\right.$ ) (M.I. Municipalidad de Guayaquil, 2015). Es decir, a pesar de que todavía hay una diferencia en el costo, es posible generar valores que pueden ser competitivos con desarrollos habitacionales para vivienda social ubicados en la periferia.

En suma, este artículo ha pretendido incluir el planteamiento de propuestas teóricas en torno a la aplicación de instrumentos de gestión para el financiamiento del desarrollo urbano y vivienda social, evitando el desplazamiento de las clases sociales de menores ingresos del centro de Guayaquil (Ley \& Dobson, 2008). De igual forma, la ubicación de vivienda social en el centro complementa la discusión acerca del derecho a la ciudad (Harvey, 2013), el comercio formal, informal y las iniciativas empresariales de los grupos de menores recursos (De Soto, 2000).

\section{Conclusiones}

Existen diversos factores que pueden tener incidencia en el éxito o fracaso respecto del uso y aplicación de instrumentos de gestión: la visión de las elites económicas, las necesidades de los grupos más pobres, los problemas de seguridad y los costos de los proyectos. Sin embargo, la diversidad de enfoques no debe ser vista como un obstáculo para lograr un desarrollo integral, económico y dinámico del centro en la ciudad de Guayaquil, el cual puede ser el lugar donde coexistan, por un lado, el desarrollo económico generado por las elites sociales y, por otro, la economía informal-formal de las clases de menores ingresos. Estas dos visiones opuestas del centro no deben ser excluyentes, sino más bien complementarias. Usualmente, las políticas de renovación de centros urbanos con un enfoque principal en la atracción de inversiones suelen relegar los problemas sociales sin considerar suficientemente asuntos relacionados con la regularización de la tenencia de la propiedad, mejoramientos en la calidad de vida, regularización del comercio informal, recuperación de residencias y provisión de vivienda social. Es decir, se trata en estos casos de políticas promocionales que se concentran en la regeneración de espacios públicos, por lo cual no han tenido el éxito esperado y no han contribuido adecuadamente a la inclusión social e integral del centro.

Las visiones diversas de la ciudad (la de las clases sociales de menores ingresos y la de las elites) pueden y deben ser integradas. Para esto es esencial el análisis de los diferentes instrumentos de gestión territorial y

\footnotetext{
${ }^{6}$ El símbolo \$ corresponde a la moneda oficial en Ecuador que corresponde al Dólar estadorunidense.
} 
captación de plusvalías que pudieran ser aplicados para el caso del centro de Guayaquil, y que contribuyan al desarrollo económico y social del mismo, enmarcados a su vez en un cuerpo legal que les dé sustento jurídico necesario y que promueva el ejercicio del derecho a la vivienda de los habitantes del centro de la ciudad, a su localización, para que sean partícipes de los procesos de renovación urbana y no sean expulsados a causa de dichos procesos. El Estado se convierte, de esta forma, en el ente regulador esencial para generar las condiciones necesarias y el desarrollo de políticas que protejan a la población más vulnerable. El control sobre los usos de suelo, regulaciones, normas y permisos se convierten en los mecanismos más poderosos de los gobiernos locales para la planificación de una política de desarrollo urbano y de vivienda más justa e incluyente.

Es necesario construir desarrollos urbanos sustentables basados en la economía y el turismo de la zona, pero al mismo tiempo creando oportunidades para todos, tanto para los pobladores de los centros como para los desarrolladores urbanos; y basándose en la participación y concertación de la comunidad, a su vez que en la gestión democrática y social de la propiedad como uno de los pilares fundamentales para crear la diversidad y calidad necesaria al espacio urbano y garantizar el éxito de los proyectos de revitalización del centro urbano de Guayaquil. El derecho a la ciudad, impulsado desde la Constitución política del Ecuador y las leyes no debe ser visto como una simple utopía y una amenaza para la autonomía de los gobiernos municipales, sino como un principio integrador para asegurar un desarrollo más equitativo para todos los ciudadanos. El desarrollo económico y la inclusión de vivienda social son dos visiones diversas, pero que pueden ser compatibles e integradas por medio de la aplicación de instrumentos de recuperación de plusvalías, que se constituyen de esta manera en oportunidades más que en restricciones para la planificación y construcción de centros urbanos más prósperos e incluyentes. 


\section{Referencias bibliográficas}

Allan, H. (2010). Regeneración urbana y exclusión social en la ciudad de Guayaquil. Guayaquil: FLACSO.

Andrade, X. (2007a). "More city", less citizenship: Urban renovation and the annihilation of public space. En F. Carrion \& L. Hanley (Eds.), Urban regeneration and revitalization in the Americas (pp.107-141). Quito: FLACSO.

Andrade, X. (2007b). Disciplining urbanites in contemporary Guayaquil. Iconos, Revista de Ciencias Sociales, FLACSO, 27, 51-64. https://doi.org/10.17141/iconos.27.2007.201

Asamblea Constituyente de Ecuador (2008). Nueva Constitucion del Ecuador. Quito: Asamblea Constituyente de Ecuador.

Asamblea del Ecuador. (2016). Ley Orgánica de Ordenamiento Territorial y Gestión del Suelo, LOOTUGS. Quito: Asamblea del Ecuador.

Azevedo, P. (2001). Los centros históricos latinoamericanos y la globalización. En F. Carrión (Ed.), La Ciudad Construida, Urbanismo en América Latina (pp. 275-287). Quito: FLACSO.

Bagnera, P. (2016). El derecho a la ciudad en la producción del suelo urbano. Estudios sobre la Pobreza y Desigualdades, Documento de trabajo 5. Buenos Aires: CLACSO.

Borrero, O. (2013). Contribución de valorización o mejoras en ColombiaAnálisis de la experiencia colombiana. Boston: Lincoln Institute of Land Policy.

Calavita, N. y Mallach, A. (2009). Vivienda inclusiva, incentivos y recaptura del valor del suelo. Land Lines, 21(1), 15-21.

Candia, D. (2007). Tugurios, migración y objetivos de desarrollo del milenio. CEPAL, Serie Población y Desarrollo, 74, 1-78. Recuperado de http://repositorio.cepal.org/bitstream/handle/11362/7215/S0700011_es .pdf; jsessionid=280D74EFA299AFCECDC886235AD3D8D8? sequence $=1$

Carrion, F. (2007). The historic centre as an object of desire. En F. Carrion \& L. Hanley (Eds.), Urban regeneration and revitalization in the Americas pp. 19-35. Quito: FLACSO. 
Código Orgánico de Ordenamiento Territorial Autónomo Descentralizado, COOTAD. (2010). Borrador Proyecto de Ley Orgánica de Ordenamiento Territorial y Gestión del Suelo. Quito: COOTAD.

De Soto, H. (2000). The mystery of capital. Why capitalism triumphs in the West and fails everywhere else. New York: Basic Books.

Delgado, A. \& De Troyer, F. (2011). Modeling qualities and housing preferences for affordable new housing developments. Open House International, 36(3), 27-37.

Delgado, A. (2013). Guayaquil-City Profile. Cities, 31, 515-532.

Delgado, A. \& De Troyer, F. (2016). Housing preferences for affordable social housing projects in Guayaquil, Ecuador. International Journal of Housing Markets and Analysis. http://dx.doi.org/10.1108/IJHMA-02-20160017.R1

Diario El Expreso (2013). Concurso: Guayaquil frente al futuro. Recuperado de http://expreso.ec/historico/guayaquil-frente-al-futuro-JDGR_5189318

Espino, A. (2007). El desarrollo de viviendas de interés social en el centro histórico de la Ciudad de Panamá. Panamá: Lincoln Institute of Land Policy.

Etienne, H. (1975). Los asentamientos urbanos populares, un enfoque interpretativo. CISEPA, serie Población 9.

Fuentes, L. y Sierralta, C. (2004). Santiago de Chile, ¿ejemplo de una reestructuración capitalista global? Eure, 30(91), 7-28. https://doi.org/10.4067/s0250-71612004009100002

Furtado, F. y Acosta, C. (2012). Recuperación de plusvalías urbanas en Brasil, Colombia y otros países de América Latina: legislación, instrumentos e implementación. Cambridge: Lincoln Institute of Land Policy.

Gasic, I., Narvaez, A. y Quiroz, R. (2015). Reapropiaciones de Henri Lefebvre: Crítica, espacio y sociedad urbana. Santiago: Editorial Triángulo.

Gonzales, C. (2003). Guayaquil siglo XXI: imágenes de una nueva urbe. Guayaquil: Tropical books.

Harvey, D. (2013). Ciudades rebeldes. Del derecho de la ciudad a la revolución urbana. Madrid: Akala. 
Instituto Nacional de Estadísticas y Censos del Ecuador, INEC (2011). Censo Nacional de Población. Recuperado de http://www.ecuadorencifras.gob.ec/institucional/home/

Inzulza-Contardo, J. (2012). Latino-gentrification'? Focusing on physical and socio-economic patterns of change in Latin American inner cities. Urban Studies, 49(10), 2085-2107. https://doi.org/10.1177/0042098011423425

Inzulza-Contardo, J. (2016). Contemporary Latin American gentrification? Young urban professionals (YUPs) discovering historic neighbourhoods, Urban Geography, 37(8), 1195-1214. http://dx.doi.org/10.1080/02723638.2016.1147754h

Laviana, M. (2008). De pueblo a ciudad: evolución urbana del Guayaquil Colonial. Revista del Archivo Histórico del Guayas, 2, 47-57. Recuperado de http://digital.csic.es/bitstream/10261/78257/1/De pueblo a ciudad.pdf

Lees, L. \& Ley, D. (2008). Introduction to special issue on gentrification and public policy. Urban Studies, 45(12), 2379-2384. https://doi.org/10.1177/0042098008097098

Lefebvre, H. (1970). La revolución urbana. Madrid. Alianza Editorial.

Ley, D. \& Dobson, C. (2008). Are there limits to Gentrification? The context of impeded gentrification in Vancouver. Urban Studies, 45(12), 2471-2498. https://doi.org/10.1177/0042098008097103

López-Morales, E. (2013). Gentrificación en Chile: aportes conceptuales y evidencias para una discusión necesaria. Revista de Geografía Norte Grande, 56, 31-52. https://doi.org/10.4067/s0718-34022013000300003

Marshall, R. (2011). Waterfront in post-industrial cities. London: Spon Press.

McCarthy, J. (1998). Reconstruction, regeneration and re-imaging: The case of Rotterdam. Cities, 15(5) 337-344. http://dx.doi.org/10.1016/S02642751(98)00029-8

Ministerio de Desarrollo Urbano y Vivienda, MIDUVI. (2014). Notas Conceptuales. I Jornadas de Derecho Urbano. Quito: MIDUVI.

Molinatti, C. (2013). Financiamiento urbano a través de la movilización de plusvalías. En D. A. Erba (Ed.), Definición de políticas de suelo urbano 
en América Latina-Teoría y Práctica (p. 134). Cambridge: Lincoln Institute of Land Policy.

Moser, C. (2009). Ordinary families, extraordinary lives: Assets of poverty reduction in Guayaquil, 1978-2004. Washington D.C.: Brookings Institution Press.

M.I. Municipalidad de Guayaquil-MG. (2005). Reporte de Indicadores Urbanos. Guayaquil: Autor.

Neira, J. (2014). La ineficacia del COOTAD y de la Ley derogada por aquella en materia de regulación y control del mercado inmobiliario. Guayaquil: Universidad Católica.

Nuñez, J. (2011). El crecimiento urbano de la urbe. Entrevista realizada por autor (2011).

Rojas, E. (2004). Volver al centro: la recuperación de áreas urbanas centrales. New York: IDB Bookstore.

Sabatini, S., Rasse, A., Mora, P., y Brain, I. (2012). Es posible la integración residencial en las ciudades chilenas? Disposición de los grupos medios y altos a la integración con grupos de extracción popular. Eure, 38(115), 159-194. https://doi.org/10.4067/s0250-71612012000300008

Sánchez, B. (2014). Mercado de suelo informal y políticas de hábitat urbano en la ciudad de Guayaquil. Quito: FLACSO.

Sandroni, P. (2011). Experiencias recientes con la recuperación de plusvalías en Sao Paulo, Brasil. Camdbridge: Lincoln Institute of Land Policy.

Scarpaci, L. (2005). Plazas y barrios. Heritage tourism and globalization in the Latin American historical center. Tucson: The University of Arizona Press.

Slater, T. (2006). The eviction of critical perspectives from gentrification research. International Journal of Urban and Regional Research, 30(4), 737-757. https://doi.org/10.1111/j.1468-2427.2006.00689.x

Smolka, M. (2013). Implementing value capture in Latin America: Policies and tools for urban development. Cambridge: Lincoln Institute of Land Policy.

Swanson, K. (2007). Revanchist urbanism heads South: The regulation of indigenous beggars and street vendors in Ecuador. Antipode Journal, a 
Radical Journal of Geography, 39(4), 708-778. http://dx.doi.org/10.1111/j.1467-8330.2007.00548.x

Tingo, B., Arana, K., Reinoso, M., Guizado, R., Yañez, M., Olivo, D., et al. (2014). Análisis de las Avenidas Quito y Machala, sector comprendido entre las calles Luque y Manabi. Guayaquil: Universidad de Especialidades Espíritu Santo.

Verrewaere S. \& Wellens E. (2010). Water urbanisms, upgrading invasion settlements in the Estuary of Guayaquil-Ecuador (Masters Thesis). Asro Departement, K.U. Leuven.

Villao, A. (2015). Estudio del uso del suelo del entorno del eje vial QuitoMachala en la ciudad de Guayaquil. Guayaquil: Universidad de Especialidades Espíritu Santo.

Wong, C. (2005). Del caos al orden: Guayaquil y su desarrollo urbano actual. Revista Ciudades, 9, 179-191. Recuperado de file://localhost/Users/Anita/Downloads/Dialnet-DelCaosAlOrden2230716.pdf 